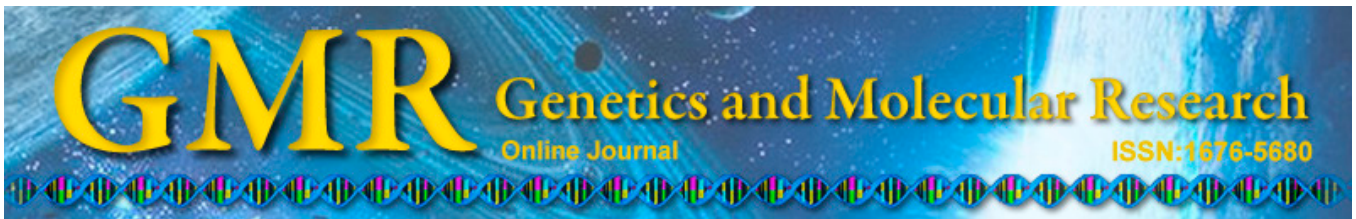

\title{
Construction and identification of recombinant adenovirus carrying human TIMP-1shRNA gene
}

\author{
Y.L. Sun, H. Xie*, H.L. Lin*, Q. Feng and Y. Liu \\ The First Hospital of Dalian Medical University, Division of Nephrology, \\ Dalian, China \\ *These authors contributed equally to this study. \\ Corresponding author: H. Xie \\ E-mail: huaxiecn@126.com
}

Genet. Mol. Res. 14 (1): 199-208 (2015)

Received March 17, 2014

Accepted July 14, 2014

Published January 16, 2015

DOI http://dx.doi.org/10.4238/2015.January.16.3

\begin{abstract}
The aim of this study was to construct the recombinant adenovirus carrying human TIMP-1shRNA gene expression system for preliminary identification to lay the foundation for the further study of gene therapy. Using the Adeno- $\mathrm{X}^{\mathrm{TM}}$ system, the recombinant adenovirus plasmid pAdeno- $\mathrm{X}^{\mathrm{TM}}$ green fluorescent protein (GFP)-tissue inhibitor of metalloprotease (TIMP)-1 small hairpin (1 shRNA) was constructed by including the target gene fragment of the TIMP-1shRNA shuttle plasmid pShuttle2-GFP-TIMP-1shRNA and the backbone plasmid pAdeno- $\mathrm{X}^{\mathrm{TM}}$ by homologous recombination in Escherichia coli. Recombinant plasmids were transfected into HEK293A cells to package the recombinant adenovirus rvAdeno- $X^{\mathrm{TM}}$ GFP-TIMP-1shRNA. The recombinant adenovirus was identified by polymerase chain reaction, and the viral titer and infection efficiency were detected using GFP. Polymerase chain reaction and restriction endonuclease digestion demonstrated that rvAdeno- $\mathrm{X}^{\mathrm{TM}}$ GFP-TIMP-1 shRNA had been successfully constructed, which has a strong ability to infect the kidney. The TIMP-1shRNA adenovirus expression vector was successfully
\end{abstract}


constructed using homologous recombination methods.

Key words: Construction of recombinant adenovirus vector; Vector; Gene transfection; RNA interference

\section{INTRODUCTION}

RNA interference is the specific transcription gene silencing process caused by binding of an RNA fragment with homology to a target gene sequence to form a double-stranded RNA; this process is widely observed in living organisms. Low et al. (2012) found that RNA interference is an important technology for guiding and promoting the differentiation of stem cells in biomedical applications. Because RNA interference technology can specifically block the expression of a target gene, it has become a powerful tool for gene function research (Charames and Bapat, 2006; Strillacci et al., 2006) and is currently the most effective gene silencing technique that can specifically inhibit the transcription of target genes, thus reducing the protein level and function (Leirdal and Sioud, 2002). Currently, this method has been widely applied for in vivo and in vitro gene function research.

Studies found that short hairpin RNA (shRNA) has a better target gene suppression effect than small interfering RNA (siRNA) (Castanotto and Rossi, 2009). RNA interference can be implemented by directly transfection of synthetic siRNA into cells, while another is to use a virus or plasmid as a vector to express the shRNA. The advantage of shRNA is that the DNA vector can synthesize large amounts of shRNA to achieve intracellular amplification; additionally, using a DNA vector, shRNA can be integrated into the genome so that cells can stably express the shRNA. The adenovirus system has several advantages, such as high efficiency, safety, short production cycle, high titers, and easy concentration, and storage (Olejniczak et al., 2010).

The adeno-associated virus vector has the advantages of high safety and low immunogenicity, and can transfect both dividing and non-dividing cells to mediate gene stable expression (Koper-Emde et al., 2004). Adenovirus has a broad host range, high infection rate, large packaging capacity, high breeding titer, no integration, good safety and stability, and easy vector preparation, which has significant advantages for in vitro transfection in gene therapy research and is currently the most widely used vector (Amalfitano and Parks, 2002; Sizemore et al., 2004; Ortolano et al., 2012). The application of recombinant adenovirus transfection has been used to effectively treat several diseases, particularly cancer. The human body contains natural matrix metalloproteinases inhibitors, including tissue inhibitors of matrix metalloproteinases (TIMP-1), which can inhibit the activity of matrix metalloproteases (MMPs). TIMP-1 combines with the MMPs through covalent bonding to form a 1: 1 complex, inhibiting MMP activity (Breyer et al., 2001). TIMP-1 specifically inhibits MMP-9, and the balance of the 2 participate in the synthesis and degradation of the extracellular matrix (Alesci et al., 2002). In this study, we used green fluorescent protein (GFP) as the reporter gene and constructed the recombinant adenovirus carrying rat TIMP-1shRNA single gene expression. Our results lay the foundation for the gene therapy of renal fibrosis.

\section{MATERIAL AND METHODS}

\section{Plasmids, strains, and cells}

The rat TIMP-1shRNA and GFP expression cassette was successfully constructed in 
the pEGFP-1 vector in a previous study. The shuttle plasmid pShuttle2 and adenovirus genomic plasmid Adeno- $\mathrm{X}^{\mathrm{TM}}$ were purchased from Clontech (Mountain View, CA, USA). Escherichia coli DH5 strains were preserved in our laboratory, and the adenovirus packaging cell line HEK293A cells were purchased from Invitrogen (Carlsbad, CA, USA).

\section{Construction of adenovirus shuttle vector of pShuttle2-EGFP-TIMP-1shRNA}

The restriction enzymes NheI and PstI were used to sequentially digest pEGFP1-TIMP-1shRNA and pShuttle2 and the enzyme digestion products were subjected to $1 \%$ agarose gel electrophoresis. The pShuttle 2 fragment (linearization plasmid expression vector) and small fragments of pEGFP-1-TIMP-1shRNA (linearization expression frame fragment) were recovered using an agarose gel Recovery Kit (TaKaRa, Shiga, Japan) and preserved at $16^{\circ} \mathrm{C}$. DNA fragments were ligated by T4 DNA ligase overnight. The ligation products were transformed fresh competent $E$. coli DH5 $\alpha$ cells, and inoculated onto LB medium containing $50 \mu \mathrm{g} / \mathrm{mL}$ kanamycin at $37^{\circ} \mathrm{C}$ overnight. Three positive clones were selected and inoculated into $5 \mathrm{~mL}$ medium containing $50 \mu \mathrm{g} / \mathrm{mL}$ kanamycin. Cells were cultured at $37^{\circ} \mathrm{C}$ in a shaking incubator $(250 \mathrm{rpm})$ overnight. Recombinant shuttle plasmids were extracted using the Plasmid Extraction Kit (TaKaRa).

\section{Recombination and identification of recombinant adenovirus plasmid pAdeno-X ${ }^{\text {TM}}$-TIMP-1shRNA}

After restriction endonucleases were used for PI-SceI and I-Ceul double enzyme digestion of pShuttle2-EGFP-TIMP-1shRNA, the digestion products were subjected to $1 \%$ agarose gel electrophoresis. The linearized products were recovered using the agarose gel extraction kit; the linearized enzyme digestion products and $\mathrm{pAdeno}-\mathrm{X}^{\mathrm{TM}}$ were preserved at $16^{\circ} \mathrm{C}$ and ligated using T4DNA ligase overnight. After phenol:chloroform:isoamyl alcohol extraction and ethanol precipitation, the purified ligase products were used to transform competent $E$. coli DH5 $\alpha$ cells. Transformed cells were inoculated into LB medium containing 100 $\mu \mathrm{g} / \mathrm{mL}$ ampicillin and cultured at $37^{\circ} \mathrm{C}$ in a shaking incubator $(250 \mathrm{rpm})$ overnight. Plasmids were extracted and further identified by PI-SceI/I-Ceul double enzyme digestion, and the correct recombinant adenovirus plasmids were used to transform competent $E$. coli DH5 $\alpha$ cells for amplification.

\section{Packaging and amplification of recombinant adenovirus pAdeno- $\mathrm{X}^{\mathrm{TM}}$-TIMP-1shRNA}

HEK293A cells were cultured in high-glucose DMEM medium (Hyclone company) containing $10 \%$ fetal bovine serum (purchased from Hyclone, Logan, UT, USA) at $37^{\circ} \mathrm{C}$ and in a 5\% $\mathrm{CO}_{2}$ incubator. HEK293A cells were inoculated onto $60-\mathrm{mm}$ diameter Petri dishes and cultured for $24 \mathrm{~h}$ to the logarithmic growth phase, which were used for transfection at $60-80 \%$ confluence. Two hundred fifty microliter of recombinant adenovirus plasmid pAdeno$\mathrm{X}^{\mathrm{TM}}$-TIMP-1 shRNA was fully linearized using the PacI enzyme and HEK293A cells were transfected according to Lipofectamine ${ }^{\mathrm{TM}} 2000$ (Invitrogen) manufacturer instructions. At 6, 12 , and $24 \mathrm{~h}$ after transfection, the morphological changes of the cells were observed under inverted phase contrast microscope. Most cells appeared to show a cytopathic effect, such as swollen, rounded, grape-like, and some cells were floating. Cells were gently removed and 
harvested, followed by lysis by repeated freezing and thawing at $-70^{\circ} \mathrm{C} / 37^{\circ} \mathrm{C} 3$ times. After brief centrifugation, the viral supernatant was collected and stored at $-20^{\circ} \mathrm{C}$. The virus supernatant was used to transfect HEK293A cells for the second time, and after amplification of virus, the viral supernatant was collected and concentrated.

\section{Identification of recombinant adenovirus pAdeno-X ${ }^{\mathrm{TM}}$-TIMP-1shRNA}

\section{Identification by fluorescence microscope}

The frozen recombinant adenovirus transfected $60-80 \%$ confluent HEK293A cells, after culturing at $37^{\circ} \mathrm{C}$ for 2-3 days, and the expression of GFP was observed under a fluorescence microscope.

\section{Polymerase chain reaction (PCR) identification}

The transfected HEK293A cells and culture medium were collected and underwent repeated freezing and thawing 3 times according to the method described above. After centrifugation, the supernatant was mixed with $1 \mathrm{mg}$ protease $\mathrm{K}, 2 \mathrm{~mL} 1 \%$ sodium dodecyl sulfate, $10 \mathrm{mM}$ EDTA, and $20 \mathrm{mM}$ Tris-HCL for digestion $2 \mathrm{~h}$. After centrifugation, the supernatant was harvested and subjected to phenol:chloroform:isoamyl alcohol extraction and ethanol precipitation. To the obtained DNA, the primers were added: EGFP-f: 5'-CTGAGCAAAGACC CCAACGAG-3', TIMP-1shRNA: 5'-AACCAGGTCCGAGTTTTTTGTC-3', and PCR amplification conditions were: denaturation for $15 \mathrm{~s}$ at $95^{\circ} \mathrm{C}, 55^{\circ} \mathrm{C}$ for $15 \mathrm{~s}, 72^{\circ} \mathrm{C}$ for $25 \mathrm{~s}, 28$ cycles, $72^{\circ} \mathrm{C}$ extension for $3 \mathrm{~min}$. PCR products were subjected to electrophoresis on a $1 \%$ agarose gel.

\section{Determination of recombinant adenovirus titers and rat in vivo infection}

After HEK293 cells were diluted to $10^{5} / \mathrm{mL}$, the cells were inoculated on an empty 96 well plate, $100 \mathrm{~mL}$ per hole, and cultured for $12 \mathrm{~h}$. The recombinant virus was harvested and serially diluted to $1 \times 10^{3}-1 \times 10^{10}$. Each dilution was inoculated at $100 \mu \mathrm{L}$ per well, and the same dilution was repeated on 3 wells. After routine culture for $6 \mathrm{~h}$, the medium was removed and fresh medium was added followed by culture for $24 \mathrm{~h}$. The cells were observed under a fluorescence microscope.

The virus titer was calculated as (pfu/mL) each well mean fluorescence $\mathrm{x} 10 /$ dilution.

Next, $0.5 \mathrm{~mL}$ recombinant adenovirus was injected at a concentration of $4 \times 10^{12} \mathrm{pfu} /$ $\mathrm{mL}$ via tail vein of rats. One, 3,7 , and 14 days after injection, the rats were sacrificed and the kidneys were removed to prepare fresh frozen sections. Expression of GFP was observed for each time point under a fluorescence microscope.

\section{RESULTS}

\section{Identification of pShuttle2-EGFP-TIMP-1shRNA recombinant adenovirus shuttle vector}

In the pShuttle2 and pEGFP-TIMP-1shRNA expression cassette fragment, there was a MluI restriction site, and the recombinant adenovirus shuttle vector pShuttle2-EGFP-TIMP- 
1shRNA was enzyme-digested using the restriction enzyme $M l u \mathrm{I}$. The digestion product was subjected to electrophoresis on a $1 \%$ agarose gel. The correct cloning was observed as a specific band at approximately 1600 base pairs, indicating the 3 clones were correct and the construction was successful (Figure 1).

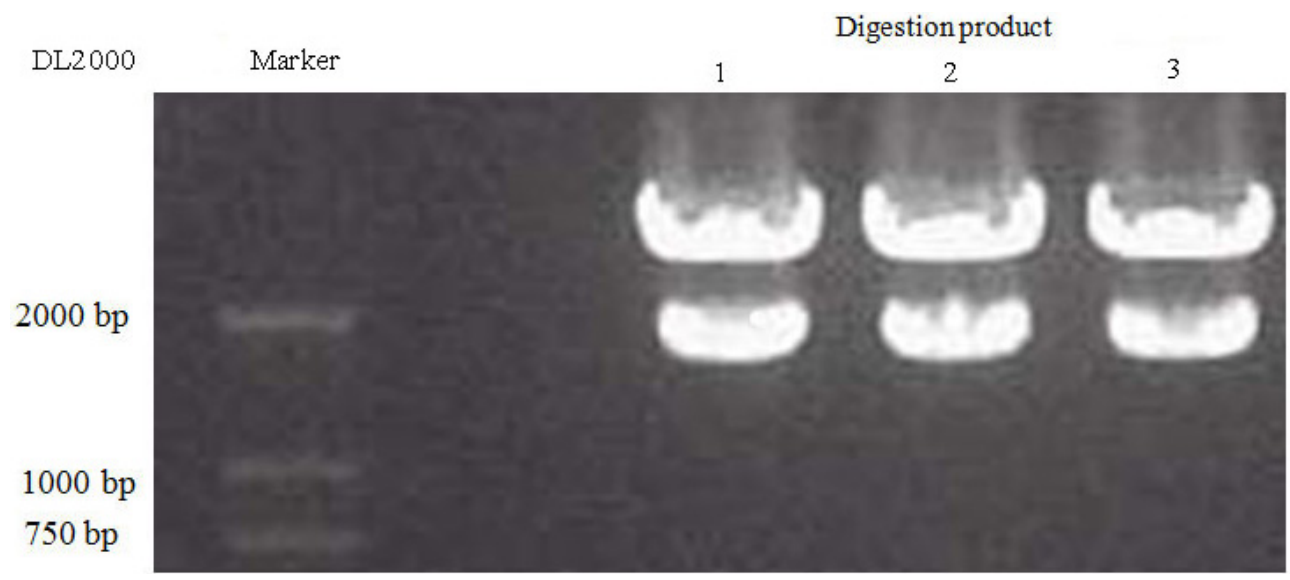

Figure 1. Identification of adenovirus shuttle vector pShuttle2-EGFP-TIMP-1shRNA bacterial colony.

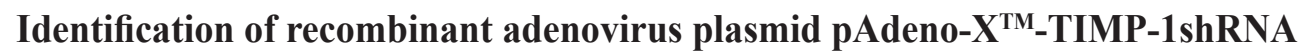

The recombinant adenovirus plasmid was constructed in E. coli DH5 $\alpha$, and 8 colonies were subjected to PCR and preliminary screening. There was an approximately 750-bp positive fragment, indicating that the 8 colonies were all positive. This indicated that pAdeno- $X^{\mathrm{TM}}$-TIMP-1shRNA was successfully constructed; after extraction of the plasmid and PI-SceI/I-Ceul double digestion, the digestion products separated by $1 \%$ agarose gel electrophoresis. A band of $2.5-5 \mathrm{~kb}$ and a band greater than $15 \mathrm{~kb}$ were observed, indicating that the construction of pAdeno- $\mathrm{X}^{\mathrm{TM}}$-TIMP-1shRNA was successful (Figure 2 and 3).

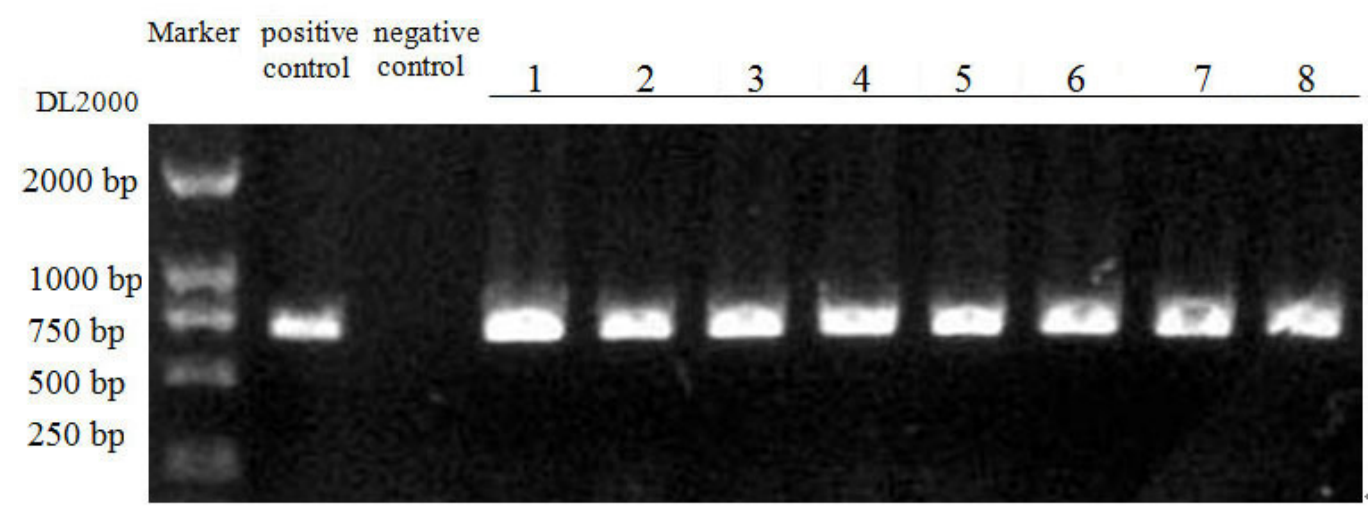

Figure 2. Identification of recombinant adenovirus plasmid pAdeno- $\mathrm{X}^{\mathrm{TM}}-\mathrm{TIMP}-1 \mathrm{shRNA}$. 


\section{Marker digestion product}

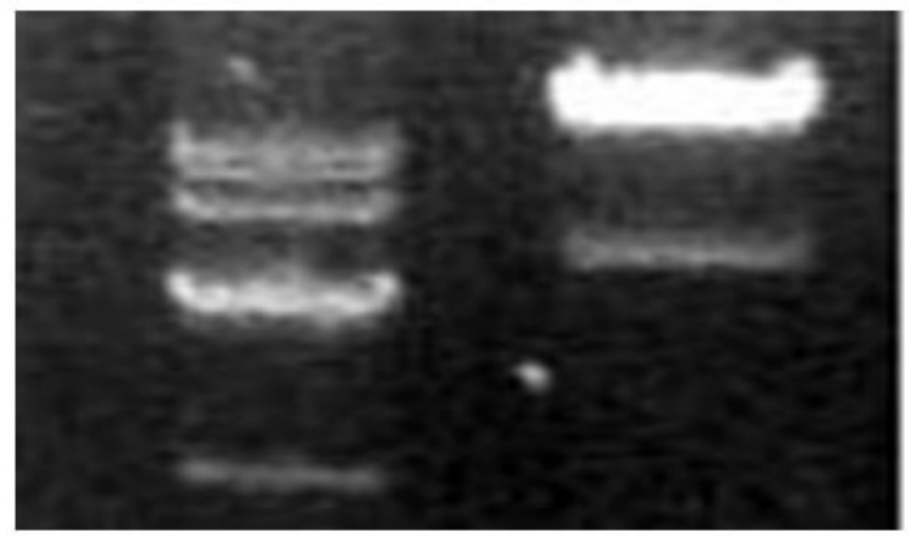

Figure 3. Identification of recombinant adenovirus plasmid pAdeno- $\mathrm{X}^{\mathrm{TM}}-\mathrm{TIMP}-1 \mathrm{shRNA}$.

\section{Identification of pAdeno- $\mathrm{X}^{\mathrm{TM}}$-TIMP-1shRNA recombinant adenovirus-transfected HEK293A cells}

\section{Lesions observed in HEK293A cells}

Liposome-encapsulated pAdeno- $\mathrm{X}^{\mathrm{TM}}$-TIMP-1shRNA homologous recombination adenovirus genomic plasmid was transfected into HEK293A packaging cells. After 1-2 days, plaque formation, cell rounding, swelling, and splitting on the wall and other lesions were observed under a light microscope (Figure 4).
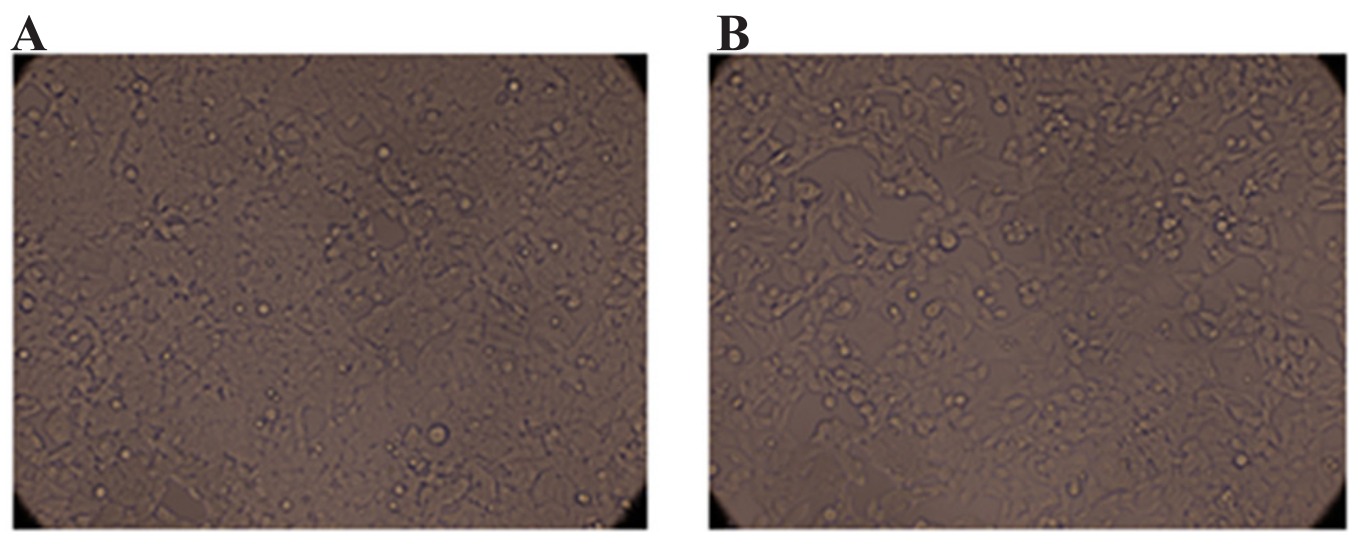

Figure 4. Morphological changes in HEK293 cells observed using light microscope. A. Normal 293 cell morphology (10X). B. CPE phenomenon after infection of virus (10X).

\section{Expression of GFP}

Recombinant adenovirus pAdeno-X $\mathrm{X}^{\mathrm{TM}}$-TIMP-1shRNA transfected HEK293A cells were seen the expression of GFP in the beginning of 8 hours of culture, and the expression increased with the time prolonging (Figure 5). 

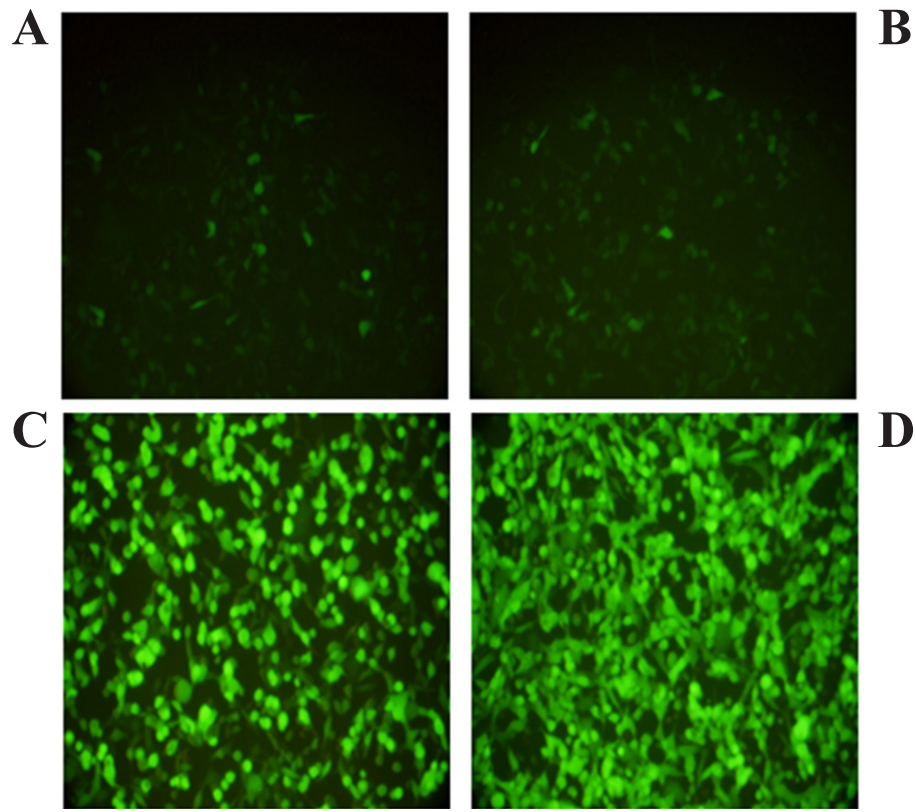

Figure 5. Changes in fluorescent protein expression. A. Six-hour-after virus-transfected 293 cells; B. 12-h-after virus-transfected 293 cells; C. 24-h-after virus-transfected 293 cells; D. 48-h-after virus-transfected 293 cells.

\section{Identification of PCR}

pAdeno- $\mathrm{X}^{\mathrm{TM}}$-TIMP-1shRNA recombinant adenovirus transfected HEK293A cells, and the genomic DNA was extracted to perform PCR, and the amplified PCR product was confirmed by $1 \%$ agarose gel electrophoresis. The 400 -bp fragment was observed, whereas uninfected cells failed to amplify this fragment, indicating that the recombinant adenovirus was constructed successfully (Figure 6).

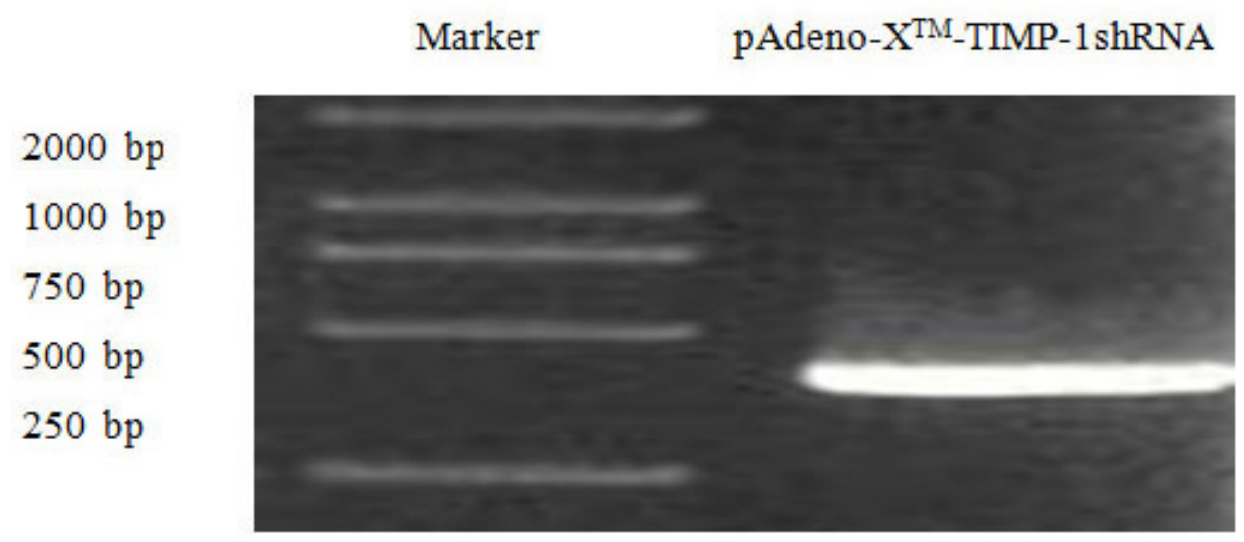

Figure 6. pAdeno- $\mathrm{X}^{\mathrm{TM}}$-TIMP-1shRNA recombinant adenovirus PCR products. 


\section{Determination of titer and infection efficiency of recombinant adenovirus}

According to the GFP counting method, the adenovirus titer was measured to be 4 $\mathrm{x} 10^{12} \mathrm{pfu} / \mathrm{mL}$. The recombinant adenovirus was used to infect rats, and the kidney of rats showed expression of GFP at 1, 3, 7, and 14 days after infection. On the 14th day, the green fluorescence was stronger (Figure 7).

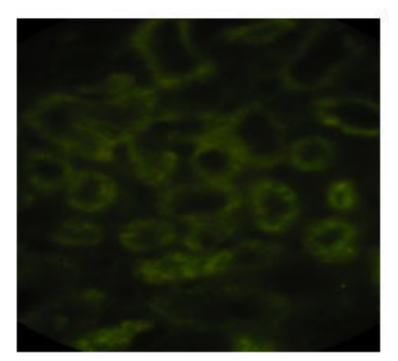

1day

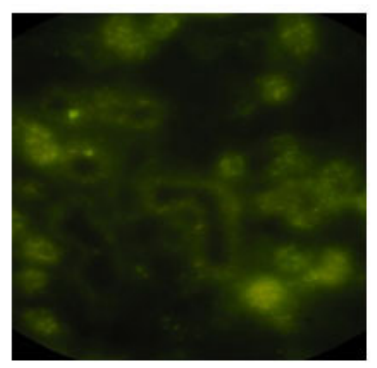

7 days

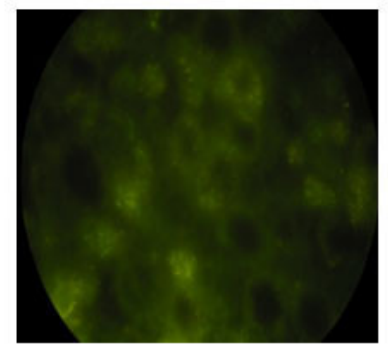

3 days

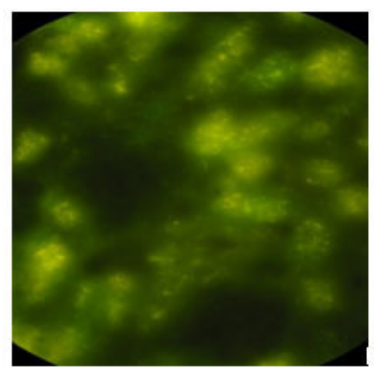

14 days

Figure 7. In vivo infection of recombinant adenovirus in rats (GFP of kidney frozen section was observed under a fluorescence microscope at different time points).

\section{DISCUSSION}

RNA interference technology can be used for post-transcriptional gene silencing and is an ideal tool for disease gene therapy because of its strict sequence specificity, high efficiency, and high stability. This method has become widely studied and has developed into an important tool for studying gene function and for tumor gene therapy (Thomas et al., 1994; Ga et al., 2005; Svennerholm and Tobias, 2008). RNA interference has been applied in the research of some human diseases, such as tumor, infection, nerve disease, and eye disease.

The TIMP-1 gene can stimulate steroidogenesis, inhibit vascular regeneration, change cellular phenotype, and inhibit apoptosis and other functions, while these functions sometimes do not depend on the inhibition of MMP activity (Boedeker, 2005; Walker et al., 2007). In addition, studies have shown that TIMP-1 can be used as a transcription factor to regulate the biological behavior of cells (Kim and Rossi, 2007). Two strategies are typically used to treat liver fibrosis, including improving the expression level of MMP to degrade the extracellular matrix and to inhibit the expression of TIMPs, which indirectly improves the expression level 
of MMPs, which reduced extracellular matrix deposition (Barker et al., 2002; Lin et al., 2002). TIMP-1 can inhibit MMP activity, resulting in extracellular matrix accumulation, which plays an important role in glomerulosclerosis. A previous study found that TIMP-1 also inhibits the apoptosis of glomerular mesangial cells in the kidney (Zhao et al., 1998).

Our TIMP-1shRNA in previous experiments was used to successfully inhibit the expression of rat mesangial cell endogenous TIMP-1. However, the in vivo inhibition of endogenous TIMP-1 expression remained unclear. Recombinant adenovirus is highly efficient for both in vitro and in vivo transfection, for a wide range of infected cells, it can infect quiescent and mitotic cells, and it does not integrate into the host cell genome; thus, the adenovirus has wide application potential in gene engineering and gene therapy (Hammann et al., 2007; Kisseleva and Brennern, 2011). In this experiment, we chose TIMP-1shRNA as the target gene fragment and recombinant adenovirus plasmid Adeno- $\mathrm{X}^{\mathrm{TM}}$ as gene therapy vector and successfully inserted the TIMP-1shRNA gene fragment into the recombinant adenovirus vector. We constructed the pAdeno- $\mathrm{X}^{\mathrm{TM}}$-TIMP-1shRNA recombinant adenovirus, which were packaged into HEK293A cells. Fluorescence measurements and amplification experiments showed that construction of the TIMP-1shRNA adenovirus vector was successful, and was then transfected into rats by tail vein injection. We found that the recombinant adenovirus can successfully infect rats' kidney, laying the foundation for further application of adenovirus expression in vivo inhibition of endogenous TIMP-1 to treat organ fibrosis.

\section{REFERENCES}

Alesci S, Ramsey WJ, Bornstein SR, Chrousos GP, et al. (2002). Adenoviral vectors can ompore adrenocortical steroidogenesis: clinical implications for natural infections and gene therapy. Proc. Natl. Acad. Sci. U. S. A. 99: 7484-7489.

Amalfitano A and Parks RJ (2002). Separating factor from fiction: assessing the potential of modified adenovirus vectors for use in human gene therapy. Curr. Gene Ther. 2: 111-133.

Baker AH, Edwards DR and Murphy G (2002). Metalloproteinase inhibitors: biological actions and therapeutic opportunities. J. Cell Sci. 115: 3719-3727.

Boedeker EC (2005). Vaccines for enterotoxigenic Escherichia coli: current status. Curr. Opin. Gastroenterol. 21 : 15-19.

Breyer B, Jiang W, Cheng H, Zhou L, et al. (2001). Adenoviral vector-mediated gene transfer for human gene therapy. Curr. Gene Ther. 1: 149-162.

Castanotto D and Rossi JJ (2009). The promises and pitfalls of RNA-interference-based therapeutics. Nature 457: 426433.

Charames GS and Bapat B (2006). Cyclooxygenese-2 knockdown by RNA interference in colon cancer. Int. J. Oncol. 28: 543-549.

Ga ZD, Chen KN, Li M, Gu J, et al (2005). Clinical significance of matrix metalloproteinase-9 expression in esophageal squamous cell carcinoma. World J. Gastroenterol. 11: 871-875.

Hammann S, Graf J, Roderfeld M and Roeb E (2007). Expression of MMPs and TIMPs in liver fibrosis - a systematic review with special emphasis on anti-fibrotic strategies. J. Hepatol. 46: 955-975.

Kim DH and Rossi JJ (2007). Strategies for silencing human disease using RNA interference. Nat. Rev. Genet. 8: $173-184$.

Kisseleva T and Brennern DA (2011). Anti-fibrogenic strategies and the regression of fibrosis. Best Pract. Res. Clin. Gastroenterol. 25: 305-317.

Koper-Emde D, Herrmann L, Sandorock B and Benecke BJ (2004). RNA interference by small hairpin RNA synthesised under control 7SK RNA promoter. Biol. Chem. 385: 791-794.

Leirdal M and Sioud M (2002). Gene silencing in mammalian cells by preformed small RNA duplexes. Biochem. Biophy. Res. Commun. 295: 744-748.

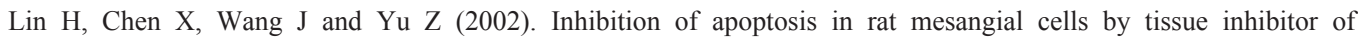
metalloproteinase-1. Kidney Int. 62: 60-69.

Low WC, Yau WW, Stanton LW, Marcy G, et al. (2012). Directing neuronal differentiation of primary neural progenitor cells by gene knockdown approach. DNA Cell Biol. 31: 1148-1153. 
Olejniczak M, Galka P and Krzyzosiak WJ (2010). Sequence-non-specific effects of RNA interference triggers and microRNA regulators. Nucleic Acids Res. 38: 1-16.

Ortolano S, Spuch C and Navarro C (2012). Present and future of adeno associated virus based gene therapy approaches. Recent Pat. Endocr. Metab. Immune Drug Discov. 6: 47-66.

Sizemore DR, Roland KL and Ryan US (2004). Enterotoxigenic Escherichia coli virulence factors and vaccine approaches. Expert Rev. Vaccines 3: 585-595.

Strillacci A, Griffoni C, Spisni E, Manara MC, et al. (2006). RNA interference as a key to knockdown overexpressed cyclooxygenase-2 gene in tumour cells. Br. J. Cancer 94: 1300-1310.

Svennerholm AM and Tobias J (2008). Vaccines against enterotoxigenic Escherichia coli. Exper. Rev. Vaccines 7: 795804.

Thomas J, Wang J, Takuba H, Sheng J, et al. (1994). A 6-hydroxydopamine-induced selective parkinsonian rat model: further biochemical and behavioral characterization. Exp. Neurol. 126: 159-161.

Walker KI, Steele D and Aguado T; Ad Hoc ETEC Technical Expert Committee (2007). Analysis of strategies to successfully vaccinate infants in developing countries against enterotoxigenic E. coli (ETEC) disease. Vaccine 25: 2545-2566.

Zhao WQ, Li H, Yaamashita K, Guo XK, et al. (1998). Cell cycle-associated accumulation of tissue inhibitor of metalloproteinase-1 (TIMP-1) in the nuclei of human gingival fibroblasts. J. Cell Sci. 111: 1147-1158. 